07

\title{
Исследование омических контактов мощных фотоэлектрических преобразователей
}

\author{
(ㄱ А.В. Малевская, В.П. Хвостиков, Ф.Ю. Солдатенков, О.А. Хвостикова, А.С. Власов, В.М. Андреев \\ Физико-технический институт им. А.Ф. Иофрфе РАН, \\ Санкт-Петербург, Россия \\ E-mail: amalevskaya@mail.ioffe.ru
}

Поступило в Редакцию 27 сентября 2018 г.

\begin{abstract}
Проведены исследования и разработана технология изготовления омических контактов мощных фотоэлектрических преобразователей на основе $\mathrm{AlGaAs} / \mathrm{GaAs}$. Исследовано влияние уровня легирования контактного слоя на величину концентрации свободных носителей и значение контактного переходного сопротивления. Проведено исследование технологии создания омических контактов толщиной $2-4 \mu \mathrm{m} \mathrm{c}$ использованием метода электрохимического осаждения слоев золота. Выявлено влияние режимов осаждения на морфологию поверхности омических контактов, монолитность структуры контактов и их электрическую проводимость.
\end{abstract}

DOI: 10.21883/PJTF.2019.01.47148.17544r

В условиях экстремальной работы концентраторных фотоэлектрических преобразователей (ФЭП) к качеству контактов предъявляются повышенные требования. Уменьшение сопротивления контактов необходимо для увеличения мощности приборов, уменьшения разогрева, связанного с протеканием токов большой плотности в фотопреобразователях концентрированного солнечного излучения при кратностях концентрирования более 1000 „солнц“, и в конечном счете для увеличения КПД концентраторных ФЭП и срока их эксплуатации. Вопросы создания омических контактов к GaAs $n$ - и p-типа проводимости рассмотрены, например, в обзорных работах $[1,2]$. При изготовлении приборных структур фотоэлектрических преобразователей и других приборов с контактными слоями на основе GaAs наиболее распространены золотосодержащие контакты [3-6], наносимые с помощью методов резистивного или электронно-лучевого испарения в вакууме.

Основной характеристикой омического контакта к полупроводнику является его переходное сопротивление, приведенное к единице площади контакта (удельное переходное контактное сопротивление). Переходное контактное сопротивление включает в себя последовательно соединенные сопротивление контактной области и сопротивление, связанное с прохождением электронами потенциального барьера. Помимо снижения величины удельного переходного контактного сопротивления среди требований, предъявляемых к омическим контактам, следует отметить необходимость воспроизводимости их электрических свойств, а также однородность характеристик ФЭП по площади. При изготовлении мощных приборов важным моментом является также процесс утолщения контактов (их верхних „проводящих“ слоев), необходимый не только для уменьшения их последовательного сопротив- ления, но и для последующего монтажа элементов ФЭП.

В настоящей работе проведены исследования технологии создания омических контактов, утолщенных с помощью электрохимического осаждения золота, для увеличения проводимости контактных шин ФЭП на основе гетероструктур AlGaAs/GaAs. Рассмотрены вопросы снижения переходного контактного сопротивления, а также оптимизации режимов изготовления гальванического покрытия для улучшения морфологии поверхности и монолитности контактов.

Исследовались фотопреобразователи мощного лазерного и концентрированного солнечного излучения на основе гетероструктур $\mathrm{AlGaAs} / \mathrm{GaAs}$ с верхним контактным слоем GaAs. Гетероструктуры выращивались методом жидкофазной эпитаксии. Главное преимущество этого метода по сравнению с аналогами заключается в возможности выращивания эпитаксиальных слоев толщиной от нескольких нанометров до сотен микрометров, характеризующихся высоким качеством, в одном технологическом процессе за относительно короткое время.

Для легирования контактного слоя GaAs в качестве акцепторной примеси был выбран германий. Было проведено исследование легирования арсенида галлия германием при температурах роста от $620^{\circ} \mathrm{C}$ (начало роста) до $520^{\circ} \mathrm{C}$ (окончание роста) для разного содержания германия в расплаве галлия. На рис. 1 показана зависимость от содержания Ge концентрации свободных носителей заряда в приповерхностной области, измеренная методом рамановской спектроскопии для слоев, выращенных из раствора-расплава с различным содержанием Ge.

Обнаружено, что концентрация дырок в приповерхностной области $N_{p} \geqslant 10^{19} \mathrm{~cm}^{-3}$, необходимая для получения ФЭП с низким контактным сопротивлением, 


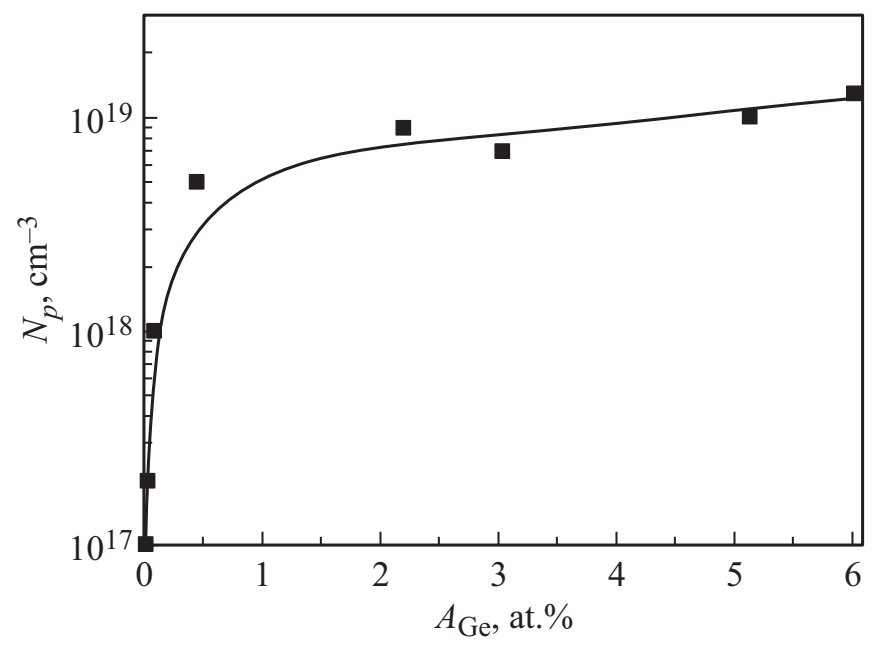

Рис. 1. Зависимость концентрации дырок $N_{p}$ в слое GaAs от содержания легирующей примеси $\mathrm{Ge}$ в расплаве $A_{\mathrm{Ge}}$.

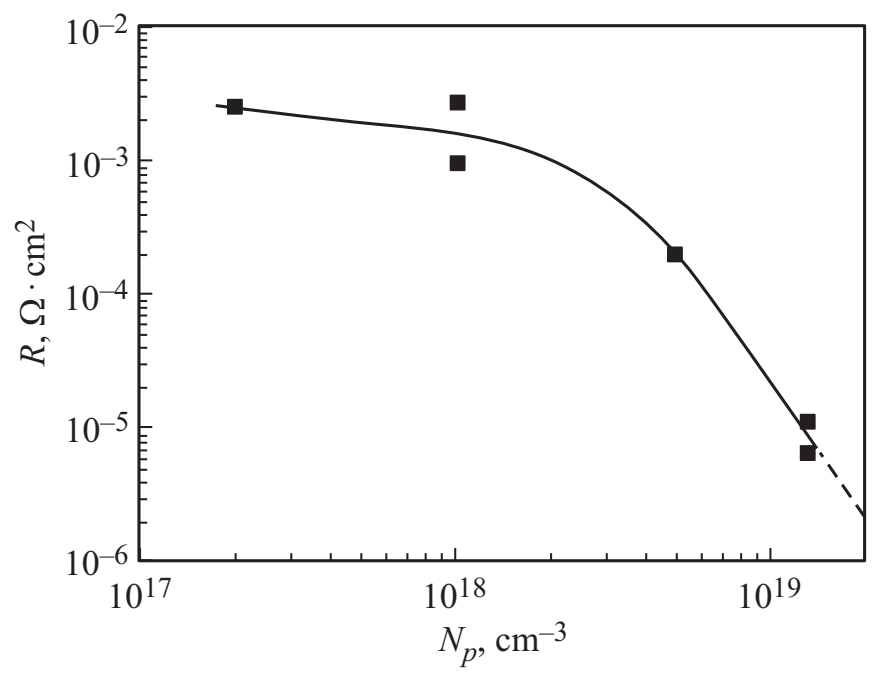

Рис. 2. Зависимость переходного контактного сопротивления от концентрации дырок в слое GaAs.

достигается при содержании германия в расплаве не менее 5 at.\%.

Омические контакты к гетероструктуре создаются в несколько стадий: проводится напыление тыльного многослойного контакта к GaAs n-типа проводимости $(\mathrm{Au}(\mathrm{Ge}) / \mathrm{Ni} / \mathrm{Au})$ и фронтального многослойного контакта к GaAs p-типа проводимости $(\mathrm{Ag}(\mathrm{Mn}) / \mathrm{Ni} / \mathrm{Au})$ общей толщиной около $0.2-0.3 \mu \mathrm{m} \mathrm{c}$ последующим вжиганием контактов при температуре $360-380^{\circ} \mathrm{C}$

При увеличении концентрации дырок в верхнем сильнолегированном контактном слое ФЭП (GaAs $p^{+}$типа проводимости) наблюдается уменьшение значений переходного контактного сопротивления (рис. 2). Так, увеличение концентрации дырок в контактном слое $p^{+}$-GaAs до $1.5 \cdot 10^{19} \mathrm{~cm}^{-3}$ позволяет изготав- ливать контакты $\mathrm{Ag}(\mathrm{Mn}) / \mathrm{Ni} / \mathrm{Au}$ со значениями удельного переходного контактного сопротивления менее $6 \cdot 10^{-6} \Omega \cdot \mathrm{cm}^{2}$.

Для увеличения проводимости контактов и обеспечения условий дальнейшего монтажа ФЭП выполняется электрохимическое утолщение фронтального и тыльного омических контактов [7]. Оптимальным материалом для электрохимического утолщения контактов является золото, которое обладает одним из самых высоких значений электрической проводимости (удельная электропроводность золота при температуpe $25^{\circ} \mathrm{C}$ равна $4.4 \cdot 10^{5} \Omega^{-1} \cdot \mathrm{m}^{-1}$ ), высокой химической стойкостью и инертностью к окружающей среде. Осаждение золота на поверхность омических контактов осуществлялось из цианистого электролита. Проведены исследования процессов осаждения золота в режиме постоянного и импульсного тока с целью увеличения равномерности процесса электрохимического осаждения и увеличения монолитности омического контакта.

Качество процесса изготовления омического контакта можно оценить по состоянию поверхности слоя. Одним из параметров, характеризующих состояние поверхности контакта, является его шероховатость, которая определяет важнейшие эксплуатационные свойства контакта, такие как износостойкость, прочность, плотность и химическая стойкость. На параметр шероховатости поверхности оказывают влияние размер гранул осаждаемого слоя и наличие пор. Соответственно снижение величины шероховатости поверхности свидетельствует об уменьшении размера гранул и отсутствии пор на гетерогранице напыленного слоя омического контакта и гальванического слоя золота. Это в свою очередь обеспечивает увеличение плотности и монолитности осаждаемого слоя, улучшение адгезии покрытия.

В результате проведенного исследования выявлена зависимость шероховатости поверхности осаждаемого слоя золота от величины коэффициента заполнения $(D)$ и частоты $(F)$ импульсного сигнала процесса электрохимического осаждения (см. таблицу). Данные для шероховатости приведены при толщине осаждаемого слоя золота порядка $3 \mu \mathrm{m}$. Измерение толщины слоя контакта и шероховатости поверхности проводилось на профилометре Dectak 3030. Установлено, что величина частоты импульсного сигнала (в пределах $30-350 \mathrm{~Hz}$ ) не оказывает существенного влияния на структуру осаждаемого слоя золота при заданном параметре коэффициента заполнения: шероховатость поверхности колеблется в пределах 120-210 А. Однако изменение коэффициента заполнения оказывает существенное влияние на структуру осаждаемого слоя: при $D=0.25$ рост слоя золота проходит однородно, величина шероховатости лежит в пределах $210 \pm 20 \AA$, а неравномерность толщины роста по структуре составляет порядка $0.5 \pm 0.1 \mu \mathrm{m}$. При увеличении коэффициента заполнения до 0.5 наблюдается небольшое снижение шероховатости до $170 \pm 20 \AA$ и 
Зависимость параметров омического контакта от режимов процесса электрохимического осаждения

\begin{tabular}{c|c|c|c}
\hline $\begin{array}{c}\text { Коэффициент } \\
\text { заполнения }\end{array}$ & Частота, $\mathrm{Hz}$ & $\begin{array}{c}\text { Шероховатость, } \\
\AA( \pm 20)\end{array}$ & $\begin{array}{c}\text { Неравномерность } \\
\text { толщины, } \mu \mathrm{m}\end{array}$ \\
\hline \multirow{5}{*}{0.25} & 30 & 170 & \\
& 60 & 210 & 0.5 \\
& 100 & 190 & \\
& 300 & 120 & \\
\hline \multirow{5}{*}{0.5} & 30 & 150 & \\
& 60 & 145 & \\
& 100 & 155 & \\
& 200 & 145 & 1.0 \\
\hline \multirow{5}{*}{0.75} & 350 & 170 & \\
& 60 & 450 & \\
& 100 & 500 & \\
& 350 & 400 & \\
\hline \multicolumn{5}{c|}{ Постояный ток } & 450 & \\
\hline
\end{tabular}

улучшение равномерности роста. При дальнейшем увеличении коэффициента заполнения до 0.75 наблюдается резкое увеличение шероховатости до $570 \AA$, неравномерности толщины слоя золота до $1 \mu \mathrm{m}$, образование пор в гальваническом слое (рис. 3,a). При проведении осаждения на постоянном токе шероховатость составляет порядка $450 \AA$, а неравномерность толщины $0.3 \mu \mathrm{m}$.

Результатом исследования стала оптимизация параметров гальванического осаждения верхних проводящих слоев многослойных контактов ФЭП, получен монолитный контакт толщиной $2-4 \mu \mathrm{m}$ с низкой степенью шероховатости поверхности и высокой адгезией к поверхности структуры при следующих параметрах осаждения: $D=0.5, F=60 \mathrm{~Hz}, R_{\alpha}=125 \pm 20 \AA$ (рис. $3, b$ ). Увеличение монолитности роста гальванического слоя омического контакта свидетельствует о снижении пористости, увеличении адгезии слоя и соответственно приводит к увеличению электрической проводимости контактных шин.

Выполнены исследования и разработана технология создания омических контактов для мощных фотоэлектрических преобразователей на основе гетероструктуры $\mathrm{AlGaAs} / \mathrm{GaAs}$. Достигнуто снижение значений удельного переходного контактного сопротивления к слоям GaAs $p^{+}$-типа до величины менее $6 \cdot 10^{-6} \Omega \cdot \mathrm{cm}^{2}$ при увеличении степени легирования контактного GaAsслоя ФЭП до $N_{p}=1.5 \cdot 10^{19} \mathrm{~cm}^{-3}$. Получены монолитные структуры контактов с шероховатостью поверхности менее $170 \pm 20 \AA$. Разработанная технология создания омического контакта позволяет снизить омические потери ФЭП за счет улучшения однород-
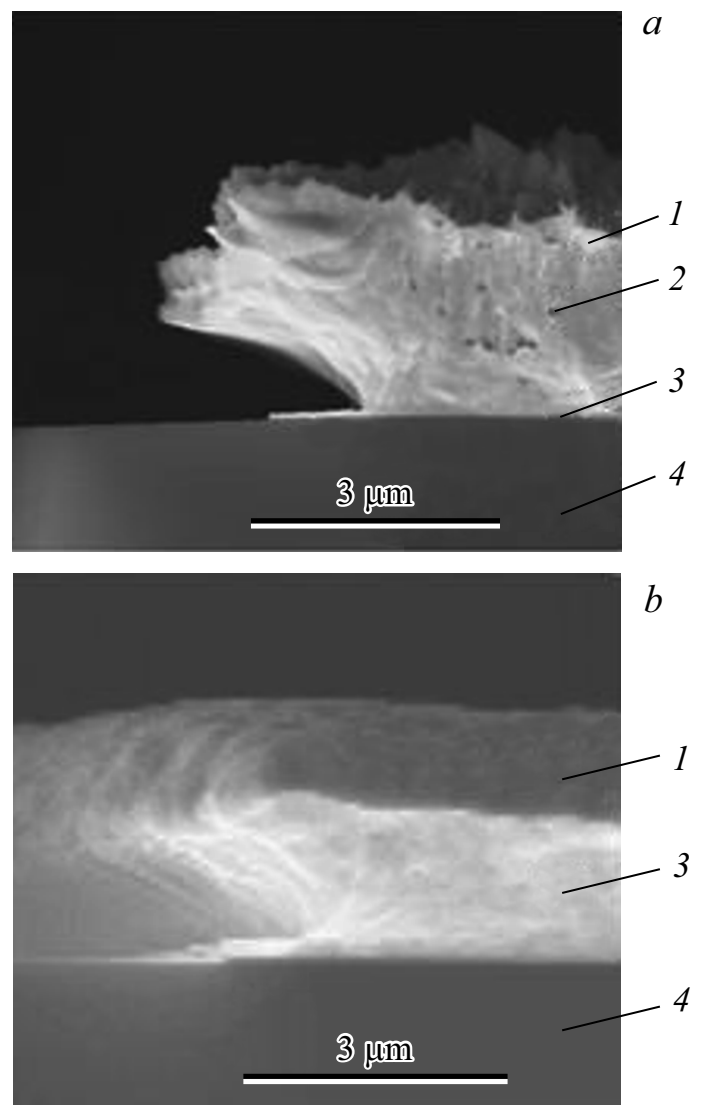

Pис. 3. Фотографии $(a, b)$ скола гетероструктуры с гальваническим слоем золота омического контакта, сделанные на сканирующем электронном микроскопе. 1 - гальванический слой золота омического контакта, 2 - поры в гальваническом слое, 3 - напыленный слой омического контакта, 4 гетероструктура.

ности осаждения материала утолщенного проводящего слоя омического контакта, улучшения его монолитности и соответственно увеличения электрической проводимости контакта, а также вследствие этого повысить КПД и мощность фотоэлектрических преобразователей.

Исследование выполнено за счет гранта Российского научного фонда (проект № 17-79-30035).

\section{Список литературы}

[1] Бланк Т.В., Гольдберг Ю.М. // ФТП. 2007. Т. 41. В. 11. C. 1281-1308. DOI: $10.1134 / \mathrm{S} 1063782607110012$

[2] Kim T.J., Holloway P.H. // Critic. Rev. Solid State Mater. Sci. 1997. V. 22. P. 239-273. DOI: $10.1080 / 10408439708241262$

[3] Cotal H., Fetzer Ch., Boisvert J., Kinsey G., King R., Hebert P., Yoon H., Karam N. // Energy Environ. Sci. 2009. V. 2. P. 174192. DOI: $10.1039 / \mathrm{B} 809257 \mathrm{E}$

[4] Szerling A., Karbownik P., Laszcz A., Kosiel K., Bugajski M. // Vacuum. 2008. V. 82. P. 977-981.

DOI: $10.1016 /$ j.vacuum.2008.01.006 
[5] Kurochka S.P., Stepushkin M.V., Borisov V.I. // Rus. Microelectronics. 2017. V. 46. N 8. P. 600-607. DOI: $10.1134 / \mathrm{S} 106373971708011 \mathrm{X}$

[6] Малевская А.В., Калиновский В.С., Ильинская Н.Д., Малевский Д.А., Контрош Е.В., Швари М.З., Андреев В.М. // ЖТФ. 2018. Т. 88. В. 8. С. $1211-1215$.

DOI: $10.21883 /$ PJTF.2018.08.46311.2591

[7] Андреев В.М., Ильинская Н.Д., Калюжный Н.А., Лантратов В.М., Малевская А.В., Минтаиров С.А. Способ изготовления чипов многослойных фотопреобразователей. Патент № 2368038. Заявка 07.12.2007. Опубл. 20.09.2009. Бюл. № 26. 